\title{
К ВОПРОСУ О ПРИМЕНИМОСТИ ТЕОРИИ МАРКОВИЦА ПРИ РАСПРЕДЕЛЕНИИ КРИПТОВАЛЮТ В ИНВЕСТИЦИОННОМ ПОРТФЕЛЕ
}

\author{
(c) 2020 Малиновский Дмитрий Алексеевич \\ аспирант, Финансовый факультет \\ Финансовый Университет при правительстве РФ, Россия, Москва \\ E-mail:dm7ml@yandex.ru
}

В исследовании произведен анализ криптовалют как инвестиционных инструментов при формировании оптимального портфеля. В статье проиллюстрировано различие эффективных границ в соответствии с теорией портфеля Марковица, при распределении портфеля между MSCI World Index и индексом криптовалюты CCI30 на разных временных горизонтах. В результате работы получилось сделать вывод касательно применимости теории Марковица на рынке криптовалют.

Ключевые слова: блокчейн, криптовалюта, биткоин, оптимальный портфель, криптовалютный рынок, высокорисковые инвестиции, индекс ССІ30, ICО

C основанием первой биткойн-биржи BitcoinMarket.com в марте 2010 года Биткойн был предложен за 0.003 USD за BTC. Популярность Биткойна и технологии блокчейна, а также новые биржи и растущее внимание средств массовой информации стали основными факторами, которые позволили поднять цену Биткойна до рекордного максимума в 19783 долл. США за биткойн в декабре 2017 года [9].

Таким образом, впечатляющий рост цен на биткойны и другие криптовалюты превратил их в спекулятивные объекты и привлек многочисленных инвесторов и трейдеров. Огромный успех Биткойна и новая технология децентрализованных криптовалют привели к тому, что в последние годы инвесторам открылся совершенно новый инвестиционный путь.

Инвестиции в криптовалюты в течение последних лет принесли огромную отдачу для инвесторов в цифровые валюты, несмотря на то, что данные инвестиции, подвержены чрезвычайной волатильности и представляют высокий риск полной потери.

За последние годы инвесторам в биткойны пришлось столкнуться с почти тринадцатью ценовыми сбоями биткойнов со снижением цен на 30-87\% [4].

Несмотря на значительное падение цен на рынке криптовалют в конце 2017 года, интерес к инвестированию в криптовалюты остается неизменным. С публикацией Digital Study 2018 немецкий почтовый банк исследовал, какие события появляются в различных сферах жизни в отношении цифровизации и инновационных финансовых тем в Германии. Репрезентативный опрос 3100 граждан Германии показал, что 29\% опрошенных классифицировали криптовалюты как интересную финансовую инвестицию. Особенно возрастная группа от 18 до 34 лет проявляет огромный интерес к криптовалютным инвестициям. Опрос показал, что в этой возрастной группе $46 \%$ интересуются криптовалютами в качестве финансовых вложений, а 29\% считают, что они хорошо или отлично знают криптовалюты. Кроме того, участники исследования указали на независимость криптовалюты от финансовой системы и перспективу чрезвычайно высокой доходности в качестве центральных драйверов для инвестиций в криптовалюту [11].

Результаты этого исследования подтверждаются опросом, проведенным Sharespost, одной из ведущих инновационных платформ для частных активов. В ходе исследования выяснилось, что, несмотря на массовую девальвацию криптовалют и наблюдаемую в прошлом высокую волатильность рынка, люди все еще очень заинтересованы в инвестициях в криптовалюты. Из всех опрошенных участников исследования $59 \%$ инвесторов и $72 \%$ потребителей заявили, что они увеличат свои инвестиции в криптовалюту в течение следующих двенадцати месяцев из-за ожидаемого повышения стоимости в будущем. 57\% всех инвесторов и 66\% потребителей в целом ожидают роста инвестиций на рынке криптовалюты в следующем году [12]. Исследование также показало, что из всех участников 
опроса более 95\% потребителей и 100\% инвесторов в настоящее время знают о криптовалютах как инвестиционном классе.

Инвестиции в криптовалюту в контексте риска

Отвечая на вопрос, касающийся самых больших проблем для широко распространенной технологии блокчейна, 55\% респондентов назвали отсутствие образования и недостаток информации [12].

Два упомянутых исследования внушительно показывают, что инвестиции на рынке криптовалюты по-прежнему классифицируются как весьма привлекательные не только для профессиональных, но и для частных инвесторов, несмотря на высокую волатильность и девальвацию цен в последние годы, особый интерес наблюдается среди молодых инвесторов в возрастной группе от 18 до 34 лет.

Огромная потенциальная отдача от инвестиций в криптовалютный рынок и описанная волатильность, похоже, не пугают большинство инвесторов.

Это обстоятельство ставит вопрос о том, в какой степени инвесторы принимают свои инвестиционные решения для криптовалют при рациональном рассмотрении описанных волатильностей.

В противоположность этому, существует вероятность того, что инвестируют преимущественно нерационально в криптовалюты, чтобы получить прибыль от спекуляций, не принимая во внимание их личную подверженность риску.

Одним из важнейших научных доказательств для принятия инвестиционных решений относительно правильного распределения активов была теория портфеля Гарри М.Марковица в 1950-х годах с его теоретическим доказательством положительного влияния диверсификации на риск и доходность всего портфеля.

Цель исследования Марковица состояла в том, чтобы предоставить математическое доказательство и научную поддержку инвесторам для формирования оптимального инвестиционного портфеля с учетом индивидуальных предпочтений инвестора с точки зрения риска, доходности и ликвидности.

Теория портфеля предполагает, что инвесторы основывают свои инвестиционные решения исключительно на двух факторах риска и доходности, что означает то, что игроки рынка хотят достичь максимально возможной доходности инвестиций для данного риска или взять наименьший возможный риск для инвестиционной эффективности [5].

Фундаментальная предпосылка состоит в том, что значительное число инвесторов принимает целостный подход к оптимизации портфеля, аналогичный теории портфеля Марковица на рынке криптовалют, и приводят распределение своего крипто-портфеля в соответствие с их индивидуальной устойчивостью к риску.

Таким образом, ниже приводятся выводы о структуре взвешивания личного портфеля инвестора между криптовалютой и инвестициями в акции в связи с индивидуальной допустимостью риска на основе научных результатов теории портфеля Марковица.

Применение теории портфеля Марковица для определения оптимальных портфелей для криптовалютных инвесторов

Как доказано, и индивидуальный риск инвестора, и опыт инвестирования оказывают существенное влияние на долю криптовалюты в инвестиционном портфеле. Отношение к риску оказывает значительное положительное влияние, а инвестиционный опыт оказывает значительное отрицательное влияние на число криптовалют в портфеле.

Ссылаясь на вопрос о том, в какой степени теория портфеля по Марковицу также может быть применена к инвестициям в недавно появившийся криптовалютный рынок, можно утверждать, что подходы Теории портфелей по Марковицу также могут быть применены к рынку криптовалют, и, поэтому, на криптовалютном рынке можно также определить оптимальные портфели.

Тем не менее, необходимо обсудить, дает ли применимость теории портфеля на текущей рыночной стадии развития криптовалютного рынка значимые утверждения о составе оптимального портфеля.

Следует учитывать, что все расчеты в теории портфеля основаны на значениях стандартного отклонения и ожидаемой прибыли из прошлого. В данной работе исследовался период с января 2015 года по март 2019 года. Таким образом, этот интервал включает сезоны, в которых криптовалюты были почти неизвестны (январь 2015 года, март 2017 года), а также так называемые периоды бума и спада, в которых необычные повышения цен в криптовалютном сегменте были зафиксированы с немедленной сильной деваль- 
вацией (октябрь 2017 - февраль 2017).

Таким образом, все изменения стоимости оказывают сильное влияние как на ожидаемую доходность, так и на стандартное отклонение. В таблице ниже показано, насколько значительный ожидаемый доход и стандартное отклонение колеблются в разные периоды времени.

Таким образом, проиллюстрировано различие эффективных границ в соответствии с теорией портфеля Марковица, основанной на распределении портфеля между MSCI World Index и индексом криптовалюты CCI30 на разных временных горизонтах.

Несмотря на то, что базовые математические вычисления в теории портфеля Марковица позволяют применять его на рынке криптовалют, огромные колебания стоимости в течение ряда различных периодов показывают, что теория Марковица портфеля может предоставить мало правдоподобных данных для распределения оптимального портфеля.

Хотя стандартное отклонение в период с января 2015 года по март 2019 года по-прежнему составляет 37,42\%, стандартное отклонение в более короткий период с января 2017 года по март 2019 года даже значительно возрастает до 48,90\% из-за крайне волатильных движений на рынке криптовалют.

Увеличение стандартного отклонения может быть правдоподобно объяснено фазой пузыря и спада между декабрем 2017 года и концом января 2018 года, таблица выше ясно показывает, что инвесторы вряд ли смогут получить значимую информацию об оптимальном распределении своего портфеля с помощью теории портфеля Марковица, основанной на исторических данных курсов криптовалют.

В первую очередь это связано с тем, что рынок криптовалют относительно молодой по сравнению с устоявшимися инвестиционными рынками, и поэтому исторические данные не очень надежны.

Кроме того, прогнозы для рынка криптовалют практически невозможны при текущем состоянии науки, что делает невозможным прогнозирование будущих ожидаемых доходов, стандартных отклонений и корреляций.

На более коротких таймфреймах рост цен на криптовалюты и акции ниже, чем на более длительных временных горизонтах, и, следовательно, ожидаемая доходность уменьшается.

Тем не менее, граница эффективности между январем 2018 года и мартом 2019 года заслуживает особого внимания, поскольку инвестор, как правило, сталкивался со значительными убытками от инвестиций в криптовалюту и акции в период с января 2018 года по март 2019 года.

Все криптовалюты с высокой рыночной капитализацией имели колоссальные убытки в период с декабря 2017 года по февраль 2018 года.

Негативным результатам портфеля можно было препятствовать только благодаря высокодоходному отбору акций с сильным увеличением стоимости в течение указанного периода времени.

В этом контексте, однако, следует учитывать, что в 2018 году мировые фондовые рынки также характеризовались исторически негативной динамикой. Инвесторам пришлось столкнуться с массовой девальвацией цен на мировых фондовых рынках, особенно в октябре, ноябре и декабре 2018 года.

В дополнение к сильным колебаниям рынка криптовалют, предположения, на основании которых была построена теория портфеля Гарри М. Марковица, также должны быть рассмотрены более подробно.

Таким образом, следует сделать вывод о весьма слабой применимости портфельной теории Марковица в данном контексте на текущем этапе развития рынка цифровых валют.

Многие из описанных фундаментальных допущений теории портфеля не соответствуют ни рынку акций, ни рынку криптовалют, так как теория портфеля Марковица предполагает совершенные рынки, на которых нет ни информационной асимметрии, ни операционных издержек.

Тем не менее, информационная асимметрия

\begin{tabular}{|l|c|c|c|c|c|c|c|c|}
\hline & \multicolumn{2}{|c|}{$01.2015-03.2019$} & \multicolumn{2}{c|}{$01.2016-03.2019$} & \multicolumn{2}{c|}{$01.2017-03.2019$} & \multicolumn{2}{c|}{$01.2018-03.2019$} \\
\cline { 2 - 10 } & SCI World & CCI30 & $\begin{array}{c}\text { MSCI } \\
\text { World }\end{array}$ & CCI30 & $\begin{array}{c}\text { MSCI } \\
\text { World }\end{array}$ & CCI30 & $\begin{array}{c}\text { MSCI } \\
\text { World }\end{array}$ & CCI30 \\
\hline Ожидаемый доход & $23,32 \%$ & $2350,09 \%$ & $26,74 \%$ & $2228,14 \%$ & $20,47 \%$ & $698,80 \%$ & $0,26 \%$ & $-83,57 \%$ \\
\hline $\begin{array}{l}\text { Стандартное } \\
\text { отклонение }\end{array}$ & $3,33 \%$ & $37,42 \%$ & $3,15 \%$ & $41,36 \%$ & $3,22 \%$ & $48,90 \%$ & $4,13 \%$ & $26,85 \%$ \\
\hline Корреляция & \multicolumn{2}{|c|}{0,1678} & \multicolumn{2}{|c|}{0,1225} & \multicolumn{2}{c|}{0,1429} & \multicolumn{2}{c|}{0,1255} \\
\hline
\end{tabular}


существует в криптовалютном секторе и может считаться значительно более высокой по сравнению с установленными рынками, такими как фондовый рынок.

Прежде всего, большинство компанийэмитентов разрабатывают технически сложные криптокены, требующие глубокого знания инвесторов, чтобы оценить возможную будущую отдачу от инвестиций. Препятствие технического понимания криптовалют приводит к естественной асимметрии информации между теми участниками рынка, которые в значительной степени понимают основные функции и технические условия децентрализованных бизнесмоделей.

Из-за отсутствия правил и должного регулирования на рынке криптовалют, инвесторы в криптовалюты и особенно вкладчики в ICO высоко подвержены значительной степени информационной асимметрии [1].

Кроме того, из-за нерегулируемой доли рынка установлено меньше каналов связи, а заслуживающие доверия информационные ресурсы весьма редки.

Отсутствие нормативных актов также приводит к тому, что эмитенты криптовалют могут действовать в основном анонимно и, таким образом, степень информационной асимметрии может доходить до абсолютного обмана инвесторов.

Также второе предположение о совершенных рынках, утверждающее, что транзакционных издержек не существует, не соответствует действительности на рынке криптовалют.
В зависимости от технологического фона цифровой монеты, транзакционные издержки возникают не только при покупке криптовалют с биржевых платформ, но и при отправке криптовалют в другие кошельки.

Затраты растут в геометрической прогрессии с ростом спроса и стоимости, в зависимости от технологической основы монеты. На пике цены биткойна в декабре 2017 года стоимость транзакции составила 37,00 долларов США по сравнению с 2,00 доллара США двумя месяцами ранее в октябре 2017 года [10].

Еще одним допущением в теории портфеля Марковица является «Homo Oeconomicus» - теоретическое изображение индивидуумов, которые действуют последовательно и рационально на рынке.

Однако, глядя на динамику цен на криптовалюты за последние четыре года, в первую очередь можно увидеть иррациональные модели поведения инвесторов криптовалюты. Основываясь на сильных взлетах и падениях ценовых изменений в криптовалютах в последние годы, проявились типичные иррациональные модели поведения инвесторов с такими перефразировками, как «Страх пропустить» (FOMO) или «Страх, неуверенность и сомнение» (FUD) в сообществах криптовалютных инвесторов.

Поэтому, в последние годы во многих случаях наблюдались иррациональные поведенческие модели инвесторов на рынке криптовалюты. Хотя Homo Oeconomicus уже является чисто теоретической конструкцией, он особенно не относится к криптовалютному рынку.

\section{Библиографический список}

1. Chod, J. A Theory of ICOs: Diversification, Agency, and Information Asymmetry. SSRN Journal, 2018.

2. CoinMarketCap. Cryptocurrency Market Capitalizations. - 2019

3. Conroy, M. J. Decision Making in Natural Resource Management: A Structured, Adaptive Approach. - John Wiley \& Sons, 2013.

4. Kelso, C. E. Bitcoin's Latest «Crash» Is Nothing New. - 2018.

5. Kremer, J. Portfoliotheorie, Risikomanagement und die Bewertung von Derivaten. - Springer Verlag, 2018.

6. Markowitz, H. Portfolio Selection. - The Journal of Finance, 1952. - PP 77-91.

7. Markowitz, H. The Early History of Portfolio Theory: 1600-1960. - Financial Analysts Journal, 1999. PP. 5-16.

8. Markowitz, H. Mean-Variance Analysis in Portfolio Choice and Capital Markets. - John Wiley \& Sons, 2000.

9. Morris, D. Bitcoin Hits a New Record High, But Stops Short of \$20,000. - Fortune, 2017.

10. Peterson, $B$. The cost of bitcoin payments is skyrocketing because the network is totally overloaded. -2017.

11. Postbank. Digital Studie 2018: Jeder dritte Deutsche zieht Kryptowährungen als Geldanlage in Betracht. - 2018.

12. SharesPost. Cryptocurrency and Blockchain Survey: Consumers Bullish, Investors Cautiously Optimistic. - 2018. 